\title{
Preservation of fertility in nature and ART*
}

\author{
Roger Gosden ${ }^{+}$and Makoto Nagano \\ Department of Obstetrics and Gynecology, McGill University, Montreal, Canada
}

\begin{abstract}
Individuals may regard reproduction as optional but sufficient number of them must be productive to perpetuate the species. The reproductive system is surprisingly vulnerable and depends, among other things, on a limited endowment of oocytes, controlled proliferation of spermatogonial stem cells and the genetic integrity of both. The developmental competence of oocytes and spermatogonial stem cells is maintained by evolved mechanisms for cellular detoxification and genomic stability, and excess or damaged cells are eliminated by apoptosis. Gonadal failure as a result of germ cell depletion can occur at any age, and from the effects of chemical cytotoxicity, disease and infection as well as genetic predisposition. Among extrinsic factors, alkylating agents and ionizing radiation are important causes of iatrogenic gonadal failure in young women and men. In animal models, there is evidence that hormonal manipulation, deletion of genes involved in apoptotic pathways and dietary manipulation can protect against natural and induced germ cell loss, but evidence in humans is absent or unclear. Assisted reproductive technologies (ARTs) provide an ensemble of strategies for preserving fertility in patients and commercially valuable or endangered species. Semen cryopreservation was the first technology for preserving male fertility, but this cannot serve prepubertal boys, for whom banking of testicular biopsies may provide a future option. In sterilized rodents, cryopreserved spermatogonial stem cells can recolonize seminiferous tubules and reinitiate spermatogenesis, and subcutaneous implantation of intact tubules can generate spermatozoa for fertilization in vitro by intracytoplasmic sperm injection. Transplantation of frozen-banked ovarian tissue is well-established for restoring cyclicity and fertility and is currently undergoing clinical evaluation for cancer patients. When restoration of natural fertility is unnecessary or reimplantation is unsafe, it is desirable to culture the germ cells from thawed tissue in vitro until they reach the stage at which they can be fertilized. Low temperature banking of immature germ cells is potentially very versatile, but storage of embryos and, to a lesser extent, mature oocytes is already practised in a number of species, including humans, and is likely to remain a mainstay for fertility preservation.
\end{abstract}

In recent years, fertility preservation has been evolving rapidly as a result of clinical imperatives and advances in technology. From a biological standpoint, each individual must survive and remain fertile long enough to have a chance of parenthood and passing on its genes. The gonads are exceptional among the major organs in being unnecessary for self-preservation, except in this genetic sense - although the advent of cloning has started to undermine this reserved role. Fertility and the species-characteristic schedule of reproductive life are adaptive traits that have evolved under selection pressure. Menopause seems to be biologically

*This review is based on the Amoroso Lecture given at the meeting of the Society for the Study of Fertility in Edinburgh in July 2000. ${ }^{\dagger}$ Address for correspondence: The Jones Institute for Reproductive Medicine, Eastern Virginia Medical School, 601 Colley Avenue, Norfolk VA 23507, USA

Email: GosdenRG@evms.edu perverse because it prematurely terminates fertility in women, although an adaptive theory exists to explain this conundrum, namely, the 'grandmother hypothesis' (Rogers, 1993). Simplistically, the most successful genetic ploy is to reproduce as soon and as rapidly as possible, to maximize the fertile lifespan and use germ cells while they are young and free from cumulated damage and ageing. The fact that this is not a universal strategy is the result of countervailing influences that can confer advantages to a slower rate of reproduction and greater investment in a few offspring (Promislow and Harvey, 1990), and this so-called K-selected strategy characterizes all primates.

Considering their pivotal roles in the life cycle, germ cells might be expected to be protected from damage or the risks of passing acquired genetic defects to offspring and wasting pregnancy effort. This was the logic behind the concept of 'immortal germplasm' promoted by August Weismann in the late Nineteenth Century (Gosden, 1996). 




Fig. 1. The disposable soma theory (redrawn from Kirkwood and Cremer, 1982).

This theory no longer has much credibility and there is no doubt that germline, like somatic, cells are subject to maladaptive deterioration and ageing. Indeed, modern gerontological theory predicts that germ cells are vulnerable.

Senescence is an ineluctable consequence of the declining force of natural selection with age, because fewer offspring are born to parents in successively older age cohorts (Williams, 1957). Natural selection does not eliminate deleterious genes if they are late-acting (especially after the menopause) and, if the genes have beneficial effects at younger ages, they may even be positively selected. This theory of antagonistic pleiotropy predicts trade-offs between benefits at young ages and costs later on. Kirkwood and Cremer (1982) contributed a physiological perspective, expressed as the 'disposable soma theory', which states that although it is theoretically possible to invest sufficiently in somatic maintenance and repair to fend off harmful age changes, natural selection may favour a balance that falls short of immortality and results in senescence (Fig. 1). The limiting resources would take many forms and include energy and nutrition, DNA repair and replacement of defective proteins, and response to cellular stress. The positive correlation between resistance to physiological stressors and lifespan in a range of mammalian species is consistent with (but not proof of) the disposable soma theory (Kapahi et al., 1999). The theory was proposed to account for somatic ageing, but it can also apply to germ cells. Indeed, similar age changes and protective mechanisms might be expected in both germ and somatic cells, even if the expression varies among specific cell types. In this review, the most salient aspects of biology and pathology relevant to long-term fecundity are considered.

Fertility preservation figures importantly among the technologies of reproduction (Box 1). One of the most marked examples is cryopreservation of gametes and embryos for patients undergoing sterilizing treatment with high-dose chemotherapy who need to protect their reproductive

\section{Box 1. Imperatives and indications for fertility preservation}

High-dose chemotherapy and pelvic irradiation Pelvic disease, for example endometriosis Surgical extirpation of gonadal tissue Incipient ovarian failure, for example premature menopause

Natural ageing of the ovaries

Preserving transgenic strains for experimental biology

Conservation of rare breeds of farm animals and endangered species

options or desire to avoid premature menopause. Demographically, the biggest factor is natural ageing, as increasing numbers of women are postponing having children until ages when fertility has declined. This trend is most advanced in northern Europe and, in the Dutch population, the peak age for child-bearing is now 30-36 years (Stephen, 1999). Oocyte fertility is often so poor and IVF success rates so low after 40 years of age that recourse to donor eggs may be required, even though most women at this age still ovulate regularly. In the second half of this review, existing and prospective options offered by assisted reproductive technology for preserving female and male fertility are considered. Not only can these methods meet the needs of patients, but some also serve useful roles in experimental biology and for conserving endangered species and rare animal breeds, strains and transgenics.

\section{In vivo preservation}

\section{Stem cell proliferation and differentiation}

Gametes develop from similar stem cell precursors of the germ line in both sexes, but from the first trimester of human pregnancy the developmental histories of the gametes of the two sexes diverge. In females, oogonial stem cells are no longer detectable by, or shortly after, birth, whereas self-renewing spermatogonial stem cells remain in testes throughout life and can propagate spermatozoa from puberty to old age. Natural selection might be expected to favour greater biological investment in the limited store of female germ cells by rigorous elimination of abnormal genotypes (Fig. 2). A number of genes involved in chromosome pairing and recombination checkpoints have already been identified in primary oocytes. For example, the gene for ataxia telangiectasia is a gene encoding a protein kinase involved in DNA metabolism, the mutated form of which causes primary ovarian failure, although some oocytes may escape and degenerate later (Xu et al., 1996). In addition, homozygous deletion of the DNA mismatch repair gene $\mathrm{m} / \mathrm{h} 1$ causes infertility in males and females as a result of halting meiosis at the pachytene stage. In addition, chromosome rearrangements during meiosis in fetuses with $45, \mathrm{XO}$ and $\mathrm{X}$ autosome translocations are associated with a zygotenepachytene checkpoint arrest reminiscent of the effect of mutations of Dmcr (Speed, 1988; Yoshida et al., 1998). 


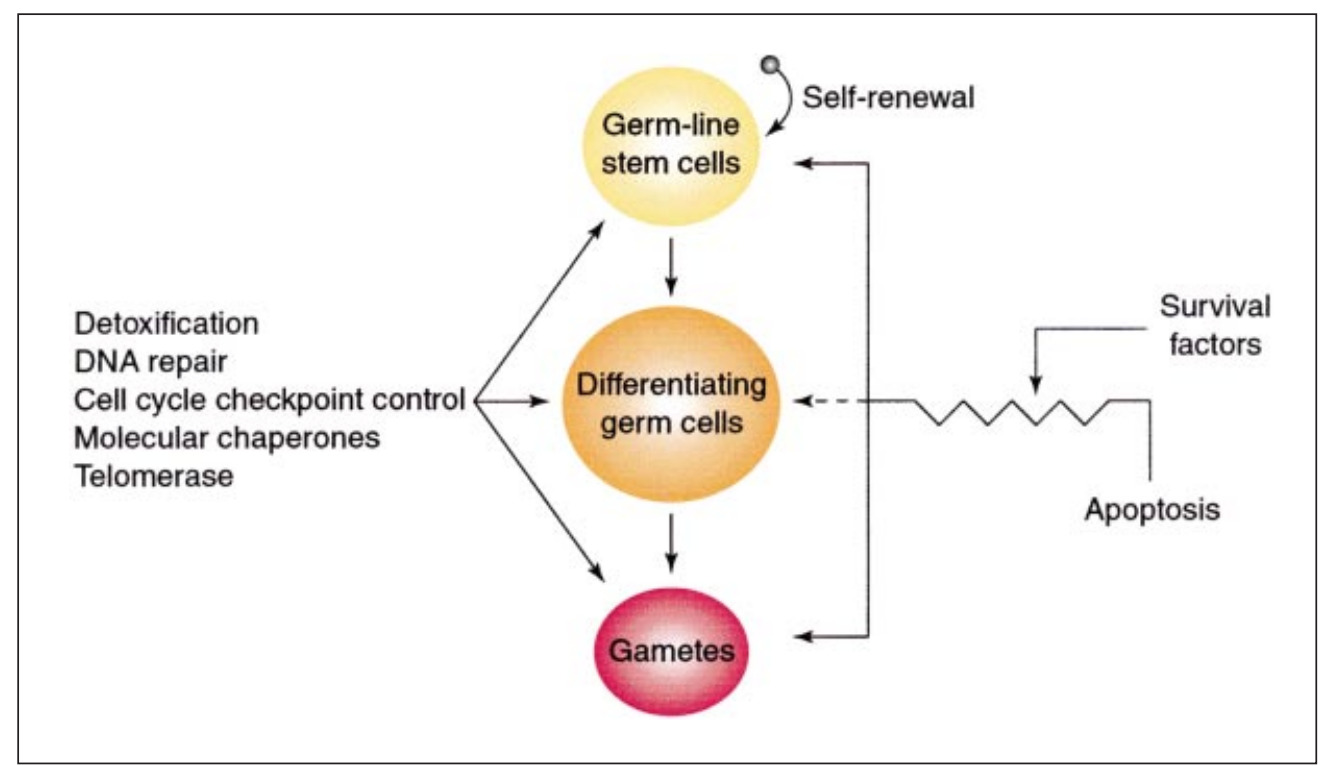

Fig. 2. Schematic summary of mechanisms involved in preserving fertility potential.

However, screening mechanisms are neither fully efficient, judging by the incidence of chromosomal nondisjunction in oocytes, nor can they account for all germ cell wastage. In the human ovary, only $15 \%$ of the initial germ cell population of 6-7 $\times 10^{6}$ remains at birth, and this number has fallen to $2.5 \times 10^{4}$ by 37 years of age. During the last 1-2 decades of reproductive life, the rate of follicle disappearance accelerates two-threefold until the ovary is virtually sterile at the time of menopause (Faddy et al., 1992). Even a slight slowing of the rate of follicle loss may have a significant impact on the number of follicles present at mid-life, and hence postpone menopause. However, no dietary or hormonal manipulation is known to affect the rate of follicle attrition in humans, although hypophysectomy and dietary restriction have pronounced and independent effects in laboratory animals (Jones and Krohn, 1961; Nelson et al., 1985). There is no convincing evidence that pharmacologically induced hypogonadotrophism can protect small follicles from natural attrition. In testes of older individuals, there is usually a decline in endocrine and spermatogenic function, although this is rarely complete even at advanced ages (Neaves et al., 1984). The most effective action for preventing testicular age changes is probably the preservation of good overall health.

The list of genes on sex chromosomes and autosomes required to establish the germ cell population in fetal gonads is growing rapidly, and their deletion can lead to ovarian dysgenesis or, at least, premature ovarian failure (for example, TIAR, Gcd, c-kit, GATA-4, DAZLA, WT-1, SOX-9, Zfx, Dia, FMR1, Bmp-4, FOXL2) (for more details, see http://ovary.stanford.edu; http://germonline.igh.cnrs.fr). Polymorphisms may account for variable numbers of female germ cells, although there is large stochastic variation (Finch and Kirkwood, 2000). In males, induced mutagenesis and spontaneous microdeletions have pinpointed Y-linked genes required for spermatogenesis, for example the $A Z F C$ region in humans, and a surprisingly large number of genes on the $\mathrm{X}$ chromosome is also required for spermatogenesis (Wang et al., 2001). In oogenesis, the key role of genes on the $X$ chromosome is known from the phenotype of Turner's syndrome (45,XO), a critical region being Xq13-q26.

During maturation, endocrine, paracrine and autocrine signals determine the rate and fate of germ cells. In the ovary, GDF-9 expression by oocytes is required for growth and differentiation beginning at early stages (Carabatsos et al., 1998). Follicles do not progress to oestrogenic stages unless stimulated with FSH (Aittomaki, 1995). Spermatogenesis can be arrested at any stage between spermatogonia and mature gametes as a result of either mutations acting cell-autonomously or of cellular interactions. A member of the TGF- $\beta$ superfamily of secreted growth factors, glial cell line-derived neurotrophic factor (GDNF), is produced by Sertoli cells with a paracrine effect (Meng et al., 2000). Overexpression of GDNF causes spermatogonia to accumulate, indicating that it serves as a brake on cell differentiation. It is plausible that the rate-limiting step in spermatogenesis is controlled by the somatic cells most necessary for germ cell development. Another example of an interaction is the production of kit-ligand (KL) in soluble and bound forms by Sertoli and granulosa cells and its binding to the receptor tyrosine kinase c-kit on the respective germ cells. When neutralizing anti-c-kit antibodies are injected into rodents, the spermatogonial death rate increases 4-15-fold, indicating that $\mathrm{KL}$ acts as an inhibitor of apoptosis (Packer et al., 1995).

Most mutant phenotypes are expressed during meiosis in male germ cells, reflecting the complexity of the process and the importance of excluding genetic errors. The genes 
have a wide range of functions in, for example, DNA mismatch repair, cell cycle control, RNA binding, the synaptonemal complex and various signalling molecules and their mediators. The phenotypes resulting from the inactivation of the genes can involve structural defects, such as impaired chromosome condensation in the case of the ubiquitin-conjugating DNA repair enzyme, HR6B (Roest et al., 1996). However, in other cases, for example the molecular chaperone, calmegin (lkawa et al., 1997), spermatozoa retain a normal morphology but are unable to bind to the oocyte.

\section{Cellular maintenance repair and apoptosis}

Germ cell multiplication and differentiation are necessary but not sufficient alone to assure fertility; quality control, protection from environmental damage and elimination of defective cells are also required. The sperm head is a highly condensed structure in which transcription and DNA repair are precluded, and only after syngamy and nuclear decondensation can repair enzymes in the ooplasm gain access to the DNA. Oocytes have an impressive ability to repair pronuclear DNA defects from recombination errors or extrinsic agents, such as UV light and chemical mutagens (Ashwood-Smith and Edwards, 1996).

The mitochondrial genome is more vulnerable than nuclear genes. High energy electrons leaking from the electron transport chain generate locally high concentrations of hydrogen peroxide, superoxide radicals $\left(\mathrm{O}_{2}^{-}\right)$and the highly toxic hydroxyl radical $(\mathrm{OH} \bullet)$, which can damage mitochondrial proteins and DNA and affect $\mathrm{Ca}^{2+}$ homeostasis and reduced glutathione. Oocytes express genes encoding a panel of antioxidant enzymes, for example, $\mathrm{Cu}-\mathrm{Zn}$-superoxide dismutase is notably abundant (EI Mouatassim et al., 1999). Dietary vitamin E supplements boost $\alpha$-tocopherol in avian spermatozoa, reducing the risk of lipid peroxidation to vulnerable membranes (Surai et al., 1998), and the relationship between nutrition and fertility has been studied intensively in farm animals. Observations in vitro of the effects of oxidants (diamide) and reducing agents indicate that free radical action is a basis for oocyte ageing. Vitamin E- and C-enriched diets also improved oocyte quality in older animals (Tarin et al., 1998), but relatively scant attention has been paid to the benefits, if any, of dietary manipulation for human fertility after 35 years of age.

Glutathione is an important component of cellular protection with a special role in decondensing the male pronucleus after fertilization. Consequently, depletion of glutathione in oocytes impairs chromatin remodelling (Sutovsky and Schatten, 1997). Embryos of transgenic mice overexpressing glutathione synthetase have higher rates of development in culture and are more resistant to diamide toxicity than are embryos of wild-type mice (Rzucidlo and Brackett, 2000). The fact that normal fertility can be improved indicates that it has not evolved optimally, but this conclusion need not be surprising if physiological adaptation has been traded-off against different functions.
Mammalian chromosomes have repeated DNA sequences at their ends - TTAGGG(n) - known as telomeres, which shorten by some $50-200$ base pairs during every cell cycle. The so-called 'immortal' cell types, germ cells and tumour stem cells, are thought to gain genomic stability in part by expressing more telomerase, a ribonucleoprotein that replaces lost telomeres (Holt and Shay, 1999). Telomerase is developmentally regulated, and is more abundant in spermatogonia and growing oocytes than at later stages of gametogenesis, and is virtually absent in mature gametes (Eisenhauer et al., 1997; Ravindranath et al., 1997). Cleaving embryos express telomerase abundantly (Betts and King, 1999) and, although deletion of the gene does not precipitate infertility, its importance in preserving the integrity of the germ line and counteracting age changes is beyond doubt.

Most germ cells in the ovary are eliminated by programmed cell death either before or after birth by the process of follicle atresia. The fate of follicles is determined by the balance of opposing actions of survival factors (for example, FSH, oestrogen, insulin-like growth factor I, epidermal growth factor, fibroblast growth factor and interleukin $1 \beta$ ) versus apoptosis-inducing factors (for example, androgens, tumour necrosis factor $\alpha$ and interleukin 6), as well as intracellular mediators such as Fas ligand, Bcl-2, Bcl-x and Bax (Gosden and Spears, 1997). Apoptosis is apparently an important mechanism controlling male germ cell development in spermatogenesis (Print and Loveland, 2000). Extensive germ cell apoptosis occurs during the first wave of spermatogenesis after birth (Wang et al., 1998), and adult male germ cells also undergo apoptosis (Henriksen and Parvinen, 1998). In addition, apoptotic cell death in spermatogenesis is frequently observed after induced mutations in mice. For instance, HSP70-2 is a heat-shock protein specific to spermatocytes and when the gene is inactivated, spermatogenesis fails because of impaired meiosis and subsequent apoptosis (Dix et al., 1996). A recent study shows that the prototype of HSP70-2, HSP70, prevents apoptosis by inhibiting apoptotic protease-acting factor 1 (APAF-1), the deletion of which also causes spermatogenic failure (Beere et al., 2000; Honarpour et al., 2000; Saleh et al., 2000).

Apoptosis is so crucial in the developing mouse ovary, that the age-specific number of follicles can be manipulated genetically. When the death gene bax is deleted by homologous recombination, young ovaries contain about three times as many oocytes as normal controls, and the difference persists for up to 2 years (Perez et al., 1999). However, the aged $b^{-/-}$animals were as infertile as controls because uterine function deteriorates early in mice. The size of the follicle store in the ovary is also increased by disruption of the gene for acid sphingomyelinase, and treatment of adult mice with sphingosine-1-phosphate can prevent follicle destruction by ionizing radiation (Morita et al., 2000). These results indicate that small lipid molecule therapy might protect fertility in cancer patients at risk of iatrogenic sterilization.

The concept of pharmacological protection is not new, 


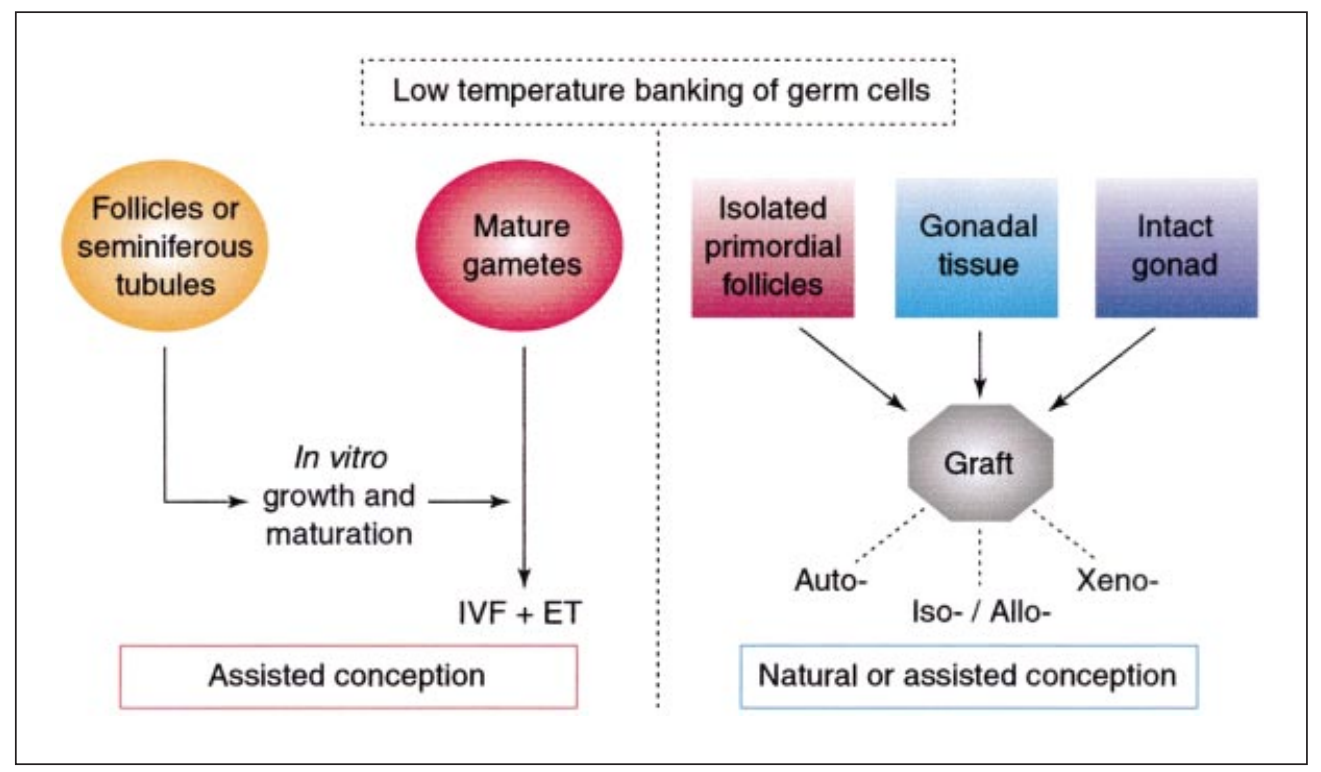

Fig. 3. Practical and theoretical options for conserving fertility by low temperature banking of germ cells and gametes. Essentially, these options involve either the growth and maturation in vitro or in vivo after transplantation or the collection of mature oocytes and spermatozoa for cryopreservation for subsequent in vitro fertilization and embryo transfer (IVF + ET).

even if now it has a more sophisticated basis. Steroid contraceptives have been administered to women with the aim of reducing ovarian cytotoxicity, although the theoretical and empirical bases were never strong (Chapman and Sutcliffe, 1981). Although the inhibition of dominant follicles by suppressing FSH with these steroids is highly effective, there is no evidence that either primordial follicle recruitment or sensitivity to cytotoxins are affected. Although convincing evidence of clinical benefit for either sex is still dubious (Waxman et al., 1987), pituitary suppression using $\mathrm{GnRH}$ analogues in rats indicates that this strategy should not be written off, at least for protecting the testis (Ward et al., 1990). The repopulation index of seminiferous tubules has been shown to be almost completely restored 10-20 weeks after administering 5 Gy of ionizing radiation and a GnRH antagonist to rats (Shetty et al., 2000). As the antagonist suppressed intratesticular testosterone, and the beneficial effect was reversed by testosterone (which, in turn, was blocked by flutamide), it was inferred that high concentrations of male hormones inhibit the growth and differentiation of spermatogonia, some of which always survive this dose of radiation.

As the prospects of long-term survival and cure for young cancer patients continue to increase, protecting their fertility is receiving higher priority (Apperley and Reddy, 1995; Blumenfeld and Haim, 1997; Meirow, 1999). Only a small proportion of patients need to have their fertility safeguarded but, until recently, only semen cryopreservation and ovarian transposition were available (Tulandi and AlTook, 1998). If reliable pharmacological alternatives become available, the relative advantages and risks of these treatments versus cryopreservation for preserving genetic parenthood will need to be assessed. However, at present, ART provides wellestablished options with new opportunities.

\section{Low temperature preservation}

Although pharmacological strategies may eventually have wide applications, clinical implementation should be cautious because of the possible harm to the health of future children after the inhibition of apoptosis in germ cells exposed to mutagens. However, there is much reassuring data about the genetic safety of long-term cryopreservation of spermatozoa and embryos. There are potential hazards from viral contamination in storage dewars, which require attention through stringent quality control (Fountain et al., 1997). Freeze-drying is unlikely to replace cryopreservation because, although lyophilized spermatozoa can fertilize oocytes, extensive molecular damage is probably incurred. Besides, low temperature preservation is versatile, proven effective and can be used for tissues, and perhaps eventually for whole organs in addition to germ cells and embryos (Fig. 3). Semen (Lass et al., 1998) and embryos (Atkinson et al., 1994) are already banked routinely for cancer patients before they undergo potentially sterilizing chemotherapy or radiotherapy. Patients receiving sub-sterilizing doses are not normally offered this service even if they are treated with potentially mutagenic alkylating agents, because no evidence has yet been presented of excess birth defects among children of former cancer patients (Green et al., 
1991). However, transgenerational effects of cyclophosphamide treatment have been reported in animals (Hales et al., 1992; Meirow et al., 2001), and these disquieting data should serve as a warning and a stimulus for continued vigilance in research.

\section{Male fertility}

The first breakthrough in reproductive cryobiology over 50 years ago was the discovery that glycerol could preserve cockerel and bull spermatozoa during freezing and thawing. The pioneers, working at Mill Hill in London, quickly extended their efforts to other reproductive and nonreproductive tissues, but success rates varied with cell size, structure and membrane permeability. Some types of cell have proved very difficult to cryopreserve and success has only recently been achieved with mouse spermatozoa, Drosophila embryos and human oocytes, and protocols are still not optimal. In addition, semen cryopreservation is not automatically effective, partly for technical reasons but also because of specimen heterogeneity. In a retrospective survey of 231 young cancer patients, half of the men produced subfertile semen samples $\left(<10^{7}\right.$ motile spermatozoa per ejaculate), and $17 \%$ did not produce enough motile spermatozoa for frozen banking (Lass et al., 1998). Sperm aspiration from the epididymis or testis for intracytoplasmic sperm injection (ICSI) can now provide a backup for cases of complete azoospermia in semen, although this is not always successful and new strategies must be sought for prepubertal boys.

The Brinster laboratory in Philadelphia first demonstrated that gonocytes from immature mouse testes can restore spermatogenesis after they are injected into the seminiferous tubules of adult hosts rendered sterile with busulphan or a mutation (Brinster and Avarbock, 1994), and the technique succeeded with both fresh and cryopreserved cells (Avarbock et al., 1996). Spermatogonial stem cells are rare in the germinal epithelium $\left(10^{-4}\right)$, but there were enough in the cell suspensions for migration between Sertoli cells and recolonization of the basal compartment of the tubule to propagate fertile spermatozoa. By extension, spermatogonia can be transfected in vitro with DNA carried by a viral vector (Nagano et al., 2000), but targeted genetic modification of the germ line is not yet feasible because it requires selection of the rare cells with homologous recombination. Moreover, the slow rate of stem cell multiplication is a limiting factor. However, germ cell transfer does offer scope for safeguarding the fertile potential of child patients when stem cells are returned via the rete testis or the vasa efferentia rather than the seminiferous tubules which are fibrous in humans (Schlatt et al., 1999; Brook et al., 2001). If this technique proves to be only partially effective in patients without a full restoration of spermatogenesis, assisted reproduction will still be needed, and will detract from the main advantage of restoring natural fertility. Hence, autografts of seminiferous tubules from frozen-thawed testicular biopsies may be a more practicable strategy for prepubertal patients. Enough mature spermatozoa can probably be generated in a subcutaneous graft for an attempt at fertilization using ICSI (Gosden et al., 2000).

\section{Female fertility}

Female fertility has the natural advantage of involving only one ovulation per month, compared with males who need to produce almost $10^{8}$ spermatozoa each day, but the quality of the oocytes and embryos and their resistance to freeze-thawing is highly variable. Since it was first reported by Trounson and Mohr (1983), human embryo banking has become a mainstay of ART, although it is used mainly with spare embryos to avoid repetition of an entire IVF cycles rather than for fertility preservation per se.

In principle, it is more desirable to store oocytes than embryos, but the technology has proved much more difficult in practice, at least in humans and in animal oocytes, which are sensitive to chilling and have delicate spindles and, in some cases (for example, cows and pigs) have a high lipid content. Apart from cryosurvival, a chief concern has been depolymerization of the metaphase spindle, which causes dispersion of chromosomes and production of potentially aneuploid conceptuses. After a short flurry of clinical reports in the mid-1980s, oocyte cryopreservation was voluntarily suspended. A decade later, pregnancies were reported again, and the better results were attributed to the use of propanediol as the cryoprotectant and ICSI for bypassing a hardened zona (Porcu et al., 1997). Nevertheless, pregnancy rates remain below those obtained after embryo cryopreservation, and confidence will have to be raised before it is used widely as an insurance against premature ovarian failure or to preserve fertility after natural waning of ovarian function. There have also been experimental and clinical reports of ultra-rapid freezing (vitrification), which may avoid the problem of sensitivity to chilling injury, although the exceptionally high concentrations of cryoprotectants raise other concerns. Optimal cryopreservation requires a delicate balance to be made between preventing ice crystal formation and solute effects on the one hand and toxicity on the other; no protocol apparently can yet be considered to be optimal.

In addition, there is the possibility of preserving the thousands of immature follicles in ovarian tissue. These follicles might be used to generate embryos using ART or to restore fertility naturally by grafting, which provides the dividend of reversing hypo-oestrogenism and menopausal changes. British pioneers of cryobiology obtained some early successes in the 1950s by cooling ovarian tissue to $-79^{\circ} \mathrm{C}$ in $15 \%$ glycerol and thawing it rapidly. Although the low permeability of glycerol makes it an unsatisfactory cryoprotectant, evidence of oestrogen secretion was obtained from isografts in rats (Parkes and Smith, 1952) and, in one trial in mice, fertility was restored after orthotopic ovarian grafting (Parrott, 1960). Advances in cryotechnology now enable extension to the larger ovaries of farm 
animals and humans using autografts or xenografts in immunodeficient mice (Newton et al., 1996; Baird et al., 1999; Weissman et al., 1999). These data have given impetus to bank cortical tissue for patients, and attempts are now being made to autotransplant the thawed tissue to restore cyclicity and perhaps fertility (Oktay and Karlikaya, 2000; Radford et al., 2001). In laboratory and farm animals, isolated primordial follicles (Carroll and Gosden, 1993) and cortical tissue slices (Harp et al., 1994; Baird et al., 1999; Candy et al., 2000) have restored ovarian function and fertility after freezing, thawing and grafting. Heterotopic grafts are an alternative to the orthotopic site, although they require the recovery of oocytes for IVF if they are to serve as more than a hormonal graft (Leporrier et al., 1987; Aubard et al., 1999). The possibility of using these techniques for children is a major incentive (Grundy et al., 2001), although transplantation may be ruled out where there is a risk of disease becoming recrudescent from gonadal tissue (Kim et al., 2001).

It is too early to predict how far this technology will serve the purposes of fertility preservation or the direction of the next phase of development. Research needs to address the safety and efficiency of tissue preservation, and may eventually enable the banking of whole organs for transplantation with vascular reanastomosis. Tissue cryopreservation has not proved to be as problematic as expected, but many follicles are lost by ischaemia after grafting (Nugent et al., 1998).

Perhaps all of these problems will be overcome eventually by growing oocytes to maturity in vitro. Realisation of that goal will then have implications beyond fertility preservation. The technology required to reach this goal is far more demanding than that required for the routine development of zygotes to the blastocyst stage. Oocyte growth and differentiation are much more protracted and require stage-specific conditions and signals from both the external medium and cumulus-granulosa cells. The production entirely in vitro of mature oocytes from primordial follicles has only been achieved once, and occurred in a rodent species (Eppig and O'Brien, 1996). Progress is being made stepwise with different follicle stages, but some success has already been recorded after cryopreservation (Cortvrindt et al., 1996; Newton et al., 1999) as well as with farm animal and human follicles (Abir et al., 1997; Gutierrez et al., 2000). When oocytes have reached full size and are meiotically competent, nuclear maturation followed by IVF in vitro can be achieved with an efficiency that is already high enough for clinical practice (Chian et al., 2000). Although research will first have to prove that extended culture does not induce epigenetic defects (Doherty et al., 2000), full development of female and male germ cells in vitro will contribute to the ongoing revolution in reproductive technology. Such progress will certainly provide new and welcome options for fertility conservation.

This paper is dedicated by R. Gosden to Professor E. C. Amoroso in warm remembrance. He also thanks his former colleagues and students in Cambridge, Edinburgh and Leeds for enthusiastic sharing of common goals in reproductive science.

\section{References}

Key references are identified by asterisks.

Abir R, Franks S, Mobberley MA, Moore PA, Margara RA and Winston RM (1997) Mechanical isolation and in vitro growth of preantral and small antral human follicles Fertility and Sterility 68 682-688

Aittomaki (1995) Mutation in the follicle-stimulating hormone receptor gene causes hereditary hypergonadotropic ovarian failure Cell $\mathbf{8 2}$ 959-968

Apperley JF and Reddy N (1995) Mechanisms and management of treatment-related gonadal failure in chemoradiotherapy Blood Reviews 9 93-116

Ashwood-Smith MJ and Edwards RG (1996) DNA repair by oocytes Molecular Human Reproduction 2 46-51

Atkinson HG, Apperley JF, Dawson K, Goldman JM and Winston RML (1994) Successful pregnancy after embryo cryopreservation after BMT for CML Lancet 344199

Aubard Y, Piver P, Cognié Y, Fermeaux V, Poulin N and Driancourt MA (1999) Orthotopic and heterotopic autografts of frozen-thawed ovarian cortex in sheep Human Reproduction 14 2149-2154

Avarbock MR, Brinster CJ and Brinster RL (1996) Reconstitution of spermatogenesis from frozen spermatogonial stem cells Nature Medicine 2 693-696

*Baird DT, Webb R, Campbell BK, Harkness LM and Gosden RG (1999) Long-term ovarian function in sheep after ovariectomy and transplantation of autografts stored at $-196^{\circ} \mathrm{C}$ Endocrinology $140462-471$

Beere HM, Wolf BB, Cain K, Mosser DD, Mahboubi A, Kuwana T, Tailor P, Morimoto RI, Cohen GM and Green DR (2000) Heat-shock protein 70 inhibits apoptosis by preventing recruitment of procaspase- 9 to Apaf- 1 apoptosome Nature Cell Biology 2 469-475

Betts DH and King WA (1999) Telomerase activity and telomere detection during early bovine development Developmental Genetics 25 397-403

Blumenfeld Z and Haim N (1997) Prevention of gonadal damage during cytotoxic therapy Annals of Medicine 29 199-206

*Brinster RL and Avarbock MR (1994) Germline transmission of donor haplotype following spermatogonial transfer Proceedings of the National Academy of Sciences USA 9111 303-11 307

Brook PF, Radford JA, Shalet SM, Joyce AD and Gosden RG (2001) Isolation of germ cells from human testicular tissue for low temperature storage and autotransplantation Fertility and Sterility 75 269-274

Candy CJ, Wood MJ and Whittingham DG (2000) Restoration of normal reproductive lifespan after grafting of cryopreserved mouse ovaries Human Reproduction 15 1300-1304

Carabatsos MJ, Elvin J, Matzuk MM and Albertini DF (1998) Characterization of oocyte and follicle development in growth differentiation factor9-deficient mice Developmental Biology 204 373-384

Carroll J and Gosden RG (1993) Transplantation of frozen-thawed mouse primordial follicles Human Reproduction 8 1163-1167

Chapman RM and Sutcliffe SB (1981) Protection of ovarian function by oral contraceptives in women receiving chemotherapy for Hodgkin's disease Blood 58 849-851

Chian R-C, Buckett WM, Tulandi T and Tan SL (2000) Prospective randomized study of human chorionic gonadotrophin priming before immature oocyte retrieval from unstimulated women with polycystic ovarian syndrome Human Reproduction 15 165-170

Cortvrindt R, Smitz J and van Steirteghem AC (1996) A morphological and functional study of the effect of slow freezing followed by complete in vitro maturation of primary mouse ovarian follicles Human Reproduction 11 2648-2655

Dix DJ, Allen JW, Collins BW, Mori C, Nakamura N, Poorman-Allen P, Goulding EH and Eddy EM (1996) Targeted gene disruption of HSP70-2 results in failed meiosis, germ cell apoptosis and male infertility Proceedings of the National Academy of Sciences USA 93 3264-3268

Doherty AS, Mann MR, Tremblay KD, Bartolomei MS and Schultz RM (2000) Differential effects of culture on imprinted H19 expression in 
the preimplantation mouse embryo Biology of Reproduction 62 1526-1535

Eisenhauer KM, Gerstein RM, Chiu CP, Conti M and Hsueh AJ (1997) Telomerase activity in female and male rat germ cells undergoing meiosis and in early embryos Biology of Reproduction 56 1120-1125

El Mouatassim S, Guerin P and Menezo Y (1999) Expression of genes encoding antioxidant enzymes in human and mouse oocytes during the final stages of maturation Molecular Human Reproduction 5 720-725

*Eppig JJ and O'Brien MJ (1996) Development in vitro of mouse oocytes from primordial follicles Biology of Reproduction 54 197-207

Faddy MJ, Gosden RG, Gougeon A, Richardson SJ and Nelson JF (1992) Accelerated disappearance of ovarian follicles in mid-life - implications for forecasting menopause Human Reproduction 7 1342-1346

Finch CE and Kirkwood TBL (2000) Chance, Development and Aging pp 86-91 Oxford University Press, New York and Oxford

Fountain D, Ralston M, Higgins N, Gorlin JB, Uhl L, Wheeler C, Antin JH, Churchill WH and Benjamin RJ (1997) Liquid nitrogen freezers: a potential source of microbial contamination of hematopoietic stem cell components Transfusion 37 585-591

Gosden RG (1996) Cheating Time - Science, Sex and Ageing pp 153-155 WH Freeman and Co., New York

Gosden R and Spears N (1997) Programmed cell death in the reproductive system British Medical Bulletin 53 644-661

Gosden RG, Matthews SJ, Kim SS and Schlatt S (2000) Potential fertility in mice after isografting cryopreserved testicular tissue Biology of Reproduction 62 (Supplement 1) 212

Green DM, Zevon MA, Lowrie G, Seigelstein N and Hall B (1991) Congenital anomalies in children of patients who received chemotherapy for cancer in childhood and adolescence New England Journal of Medicine 325 141-146

Grundy R, Gosden RG, Hewitt M, Larcher V, Leiper A, Spoudeas HA, Walker D and Wallace WHB (2001) Fertility preservation for children treated for cancer (1): scientific advances and research dilemmas Archives of Diseases of Childhood 84 355-359

Gutierrez CG, Ralph JH, Telfer EE, Wilmut I and Webb R (2000) Growth and antrum formation of bovine preantral follicles in long-term culture in vitro. Biology of Reproduction 62 1322-1328

Hales BF, Crosman K and Robaire B (1992) Increased post-implantation loss and malformations among the $F_{2}$ progeny of male rats chronically treated with cyclophosphamide Teratology 45 671-678

Harp R, Leibach J, Black J, Keldahl C and Karow A (1994) Cryopreservation of murine ovarian tissue Cryobiology 31 336-343

Henriksen K and Parvinen M (1998) Stage-specific apoptosis of male germ cells in the rat: mechanisms of cell death studied by supravital squash preparations Tissue Cell 30 692-701

Holt SE and Shay JW (1999) Role of telomerase in cellular proliferation and cancer Journal of Cellular Physiology 180 10-18

Honarpour N, Du C, Richardson JA, Hammer RE, Wang X and Hertz J (2000) Adult Apaf-1-deficient mice exhibit male infertility Developmental Biology 218 248-258

Ikawa M, Wada I, Kominami K, Watanabe D, Toshimori K, Nishimune Y and Okabe $\mathbf{M}$ (1997) The putative chaperone calmegin is required for sperm fertility Nature 387 607-611

Jones EC and Krohn PL (1961) The effect of hypophysectomy on age changes in the ovaries of animals Journal of Endocrinology 21 497-508

Kapahi P, Boulton ME and Kirkwood TBL (1999) Positive correlation between mammalian life span and cellular resistance to stress Free Radical Biology and Medicine 26 495-500

Kim SS, Radford JA, Harris M, Varley J, Rutherford AJ, Shalet SM and Gosden RG (2001) Ovarian tissue harvested from lymphoma patients to preserve fertility may be safe for autotransplantation Human Reproduction 16 2056-2060

Kirkwood TBL and Cremer T (1982) Cytogerontology since 1881: a reappraisal of August Weismann and a review of modern progress Human Genetics 60 101-121

Lass A, Akagbosu F, Abusheikha N, Hassouneh M, Blayney M, Avery S and Brinsden P (1998) A programme of semen cryopreservation for patients with malignant disease in a tertiary infertility centre: lessons from 8 years' experience Human Reproduction 13 3256-3261
Leporrier M, von Theobald P, Roffe JL and Mueller G (1987) A new technique to protect ovarian function before pelvic irradiation Cancer $602201-2204$

* Meirow D (1999) Ovarian injury and modern options to preserve fertility in female cancer patients treated with high-dose radio-chemotherapy for hemato-oncological neoplasias and other cancers Leukemia and Lymphoma 33 65-76

Meirow D, Epstein M, Lewis H, Nugent D and Gosden RG (2001) Administration of cyclophosphamide at different stages of follicular maturation in mice: effects on reproductive performance and fetal malformations Human Reproduction 16 632-637

Meng X, Lindahl M, Hyvönen ME et al. (2000) Regulation of cell fate decision of undifferentiated spermatogonia by GDNF Science 287 1489-1493

Morita Y, Perez GI, Paris F et al. (2000) Oocyte apoptosis is suppressed by disruption of the acid sphingomyelinase gene or by sphingosine-1. phosphate therapy Nature Medicine 6 1109-1114

Nagano M, Shinohara T, Avarbock MR and Brinster RL (2000) Retrovirusmediated gene delivery into male germ line stem cells FEBS Letters $\mathbf{4 7 5}$ 7-10

Neaves WB, Johnson L, Porter JC, Parker CR, Jr and Petty CS (1984) Leydig cell numbers, daily sperm production and serum gonadotropin levels in aging men Journal of Clinical Endocrinology and Metabolism 59 756-763

Nelson JF, Gosden RG and Felicio LS (1985) Effect of dietary restriction on estrous cyclicity and follicular reserves in aging C57BL/6J mice Biology of Reproduction 32 515-522

Newton H, Aubard Y, Rutherford A, Sharma V and Gosden R (1996) Low temperature storage and grafting of human ovarian tissue Human Reproduction 11 1487-1491

Newton H, Picton H and Gosden RG (1999) In vitro growth of oocytegranulosa cell complexes obtained from cryopreserved ovine tissue Journal of Reproduction and Fertility 115 141-150

Nugent D, Newton H, Gallivan L and Gosden RG (1998) Protective effect of vitamin $\mathrm{E}$ on ischaemia-reperfusion injury in ovarian grafts Journal of Reproduction and Fertility 114 341-346

Oktay K and Karlikaya G (2000) Ovarian function after transplantation of frozen, banked autologous ovarian tissue New England Journal of Medicine 3421919

Packer Al, Besmer P and Bachvarova RF (1995) Kit ligand mediates survival of type A spermatogonia and dividing spermatocytes in postnatal mouse testes Molecular Reproduction and Development 42 303-310

Parkes AS and Smith AU (1952) Regeneration of rat ovarian tissue grafted after exposure to low temperatures Proceedings of the Royal Society of London 140 455-467

Parrott DVM (1960) The fertility of mice with orthotopic ovarian grafts derived from frozen tissue Journal of Reproduction and Fertility 1 230-241

*Perez GI, Robles R, Knudson CM, Flaws JA, Korsmeyer SJ and Tilly JL (1999) Prolongation of ovarian lifespan into advanced chronological age by Bax-deficiency Nature Genetics 21 200-203

Porcu E, Fabbri R, Seracchiolo R, Ciotti PM, Magrini $O$ and Flamigni C (1997) Birth of a healthy female after intracytoplasmic sperm injection of cryopreserved human oocytes Fertility and Sterility 68 724-726

Print CG and Loveland KL (2000) Germ cell suicide: new insights into apoptosis during spermatogenesis BioEssays 22 423-430

Promislow DEL and Harvey PH (1990) Living fast and dying young: a comparative analysis of life-history variation among mammals Journal of Zoology 220 417-437

Radford JA, Lieberman BA, Brison DR et al. (2001) Orthotopic reimplantation of cryopreserved ovarian cortical strips after high-dose chemotherapy for Hodgkin's lymphoma Lancet 357 1172-1175

Ravindranath N, Dalal R, Solomon B, Djakiew D and Dym M (1997) Loss of telomerase activity during male germ cell differentiation Endocrinology 138 4026-4029

Roest HP, van Klaveren J, de Wit J et al. (1996) Inactivation of the HR6B ubiquitin-conjugating DNA repair enzyme in mice causes male sterility associated with chromatin modification Cell 86 799-810

Rogers AR (1993) Why menopause? Evolutionary Ecology 7 406-420

Rzucidlo SJ and Brackett BG (2000) Developmental patterns of zygotes from transgenic female mice with elevated tissue glutathione Journal of Experimental Zoology 286 173-180 
Saleh A, Srinivasula SM, Balkir L, Robbins PD and Alnemri ES (2000) Negative regulation of the Apaf- 1 apoptosome by Hsp70 Nature Cell Biology 2 476-483

Schlatt S, Rosiepen G, Weinbauer GF, Rolf C, Brook PF and Nieschlag E (1999) Germ cell transfer into rat, bovine, monkey and human testes. Human Reproduction 14 144-150

Shetty G, Wilson G, Huhtaniemi I, Shuttlesworth GA, Reissmann T and Meistrich ML (2000) Gonadotropin-releasing hormone analogs stimulate and testosterone inhibits the recovery of spermatogenesis in irradiated rats Endocrinology 141 1735-1745

Speed RM (1988) The possible role of meiotic pairing anomalies in the atresia of human fetal oocytes Human Genetics 78 260-266

Stephen EH (1999) Postponement of childbearing and its effects on the prevalence of subfertility. In Female Reproductive Aging pp 59-70 Eds ER te Velde et al. Parthenon, New York and London

Surai P, Kostjuk I, Wishart G, Macpherson A, Speake B, Noble R, lonov I and Kutz $\mathbf{E}$ (1998) Effect of vitamin $E$ and selenium supplementation of cockerel diets on glutathione peroxidase activity and lipid peroxidation susceptibility in sperm, testes and liver Biological Trace Element Research 64 119-132

Sutovsky P and Schatten G (1997) Depletion of glutathione during bovine oocyte maturation reversibly blocks the decondensation of the male pronucleus and pronuclear apposition during fertilization Biology of Reproduction $\mathbf{5 6}$ 1503-1512

Tarin JJ, Vendrell FJ, Ten J and Cano A (1998) Antioxidant therapy counteracts the disturbing effects of diamide and maternal ageing on meiotic division and chromosomal segregation in mouse oocytes Molecular Human Reproduction 4 281-288

Trounson A and Mohr L (1983) Human pregnancy following cryo- preservation, thawing and transfer of an eight cell embryo Nature 305 707-709

Tulandi T and Al-Took S (1998) Laparoscopic ovarian suspension before irradiation Fertility and Sterility 70 381-383

Wang PJ, McCarrey JR and Page DC (2001) An abundance of X-linked genes expressed in spermatogonia Nature Genetics 27 422-6.

Wang RA, Nakane PK and Koji T (1998) Autonomous cell death of mouse male germ cells during fetal and postnatal period Biology of Reproduction 58 1250-1256

Ward A, Robinson J, Furr BJA, Shalet S and Morris ID (1990) Protection of spermatogenesis in rats from the cytotoxic procarbazine by the depot formulation of Zoladex, a gonadotrophin-releasing hormone agonist Cancer Research 50 568-574

Waxman JH, Ahmed R, Smith D, Wrigley PF, Gregory W and Shalet S (1987) Failure to preserve fertility in patients with Hodgkin's disease Cancer Chemotherapy and Pharmacology 19 159-162

Weissman A, Gotlieb L, Colgan T, Jurisicova A, Greenblatt EM and Casper RF (1999) Preliminary experience with subcutaneous human ovarian cortex transplantation in the NOD-SCID mouse Biology of Reproduction 60 1462-1467

Williams GC (1957) Pleiotropy, natural selection and the evolution of senescence Evolution 11 398-411

Xu Y, Ashley T, Brainerd EE, Bronson RT, Meyn MS and Baltimore D (1996) Targeted disruption of ATM leads to growth retardation, chromosomal fragmentation during meiosis, immune defects, and thymic lymphoma Genes and Development 10 2411-2422

Yoshida K, Kondoh G, Matsuda Y, Habu T, Nishimune Y and Morita T (1998) The mouse RecA-like gene Dmc1 is required for homologous chromosome synapsis during meiosis Molecular Cell 1 707-718 